\title{
University student attitudes to prosocial bystander behaviours
}

Authors: Sarah E Hennelly ${ }^{1}$, Sofia Hussain ${ }^{2}$, Tristan Hale ${ }^{3}$ Martha Cadle ${ }^{4}$, Joanne Brooke ${ }^{5}$ \& Emma L Davies 1

1. Department of Psychology, Oxford Brookes University, Oxford, OX3 0BP, United Kingdom

2. Directorate of Academic and Student Affairs, Oxford Brookes University, Oxford, OX3 0BP, United Kingdom

3. Directorate of Estates and Facilities Management, Oxford Brookes University, Oxford OX3 0BP, United Kingdom

4. Faculty of Health and Life Sciences, Oxford Brookes University, Oxford OX3 0FL, United Kingdom

5. Faculty of Health, Education and Life Sciences, Birmingham City University, Birmingham, B15 3TN, United Kingdom

Corresponding author: Sarah E Hennelly sarahehennelly@brookes.ac.uk

All authors contributed to the design of the study and collected the data. SEH and ELD wrote the draft report. SH, TH, MC and JB contributed to specific sections on hate crimes, university reporting mechanisms and consent workshops. All authors agreed on the final version of the manuscript.

Acknowledgements: We are grateful to the participants for sharing their experiences and views and the students who helped with constructing the survey items. This work was supported by the Office for Students, 
UK university student attitudes to intervening in and reporting assault and harassment

\section{STRUCTURED ABSTRACT}

Purpose: Half of British university students experience assault and harassment behaviours; few report them. Bystander intervention training has been recommended as a means of reducing these behaviours, but there is little evidence about their potential effectiveness in UK contexts. This study sought to understand UK students' attitudes towards reporting and intervening in sexual assault, harassment, and hate crimes.

Design: A mixed methods cross sectional survey $(\mathrm{N}=201 ; 75.6 \%$ women) was conducted in one British university. Open text data were analysed using thematic analysis.

Findings: Students considered harassment and assault unacceptable, and were confident to intervene in and likely to report incidents. However, fear of backlash was a barrier to intervening and reporting, and they felt that victims should decide whether to report incidents. Students perceived perpetrators as being ignorant about what constitutes consent, harassment, and assault. They identified a need for university community education about this and how to report incidents and support peers.

Research limitations/implications: This cross sectional survey was conducted at one UK University. The data might not reflect other students' attitudes, and may be subject to response bias.

Practical implications: University community bystander training should be acceptable, report and support systems might be utilised by students. This may have potential to reduce prevalence and increase reporting.

Originality: This is the first study to investigate UK student attitudes to prosocial bystander behaviours.

Key words: Bystander intervention, reporting, attitudes, harassment, assault, hate crime, university. 
UK university student attitudes to intervening in and reporting assault and harassment

Article classification: Research article.

Running heads: UK university student attitudes to intervening in and reporting assault and harassment. 
UK university student attitudes to intervening in and reporting assault and harassment

\section{University student attitudes to prosocial bystander behaviours}

\section{INTRODUCTION}

Assault and harassment are prevalent on university campuses in the United Kingdom (UK). Incidents can have physical, psychological, and educational consequences (NUS, 2019; Towl and Walker, 2019). The UK National Union of Students (NUS) conducted an online cross-sectional survey with students, and produced a series of reports to understand assault and harassment on university campuses. The 'No Place for Hate' report found that one in six of the 9225 students who responded (16\%) felt that they had been the victim of hate crimes. Victims attributed incidents to their race or ethnicity (30\%), sexual orientation (24\%), religion or belief (19\%), gender identity (16\%), and disability (6\%) (Office for National Statistics, NUS, 2011a; NUS, 2012). Chinese, Asian, Black/Black British, Asian/Asian British, gay, lesbian, bisexual, Jewish, Islamic, Sikh, transgender, and/or visibly disabled students were most likely to experience hate crimes (NUS, 2012). The Equality and Human Rights Commission (EHRC) is currently analysing responses to an online survey on racial harassment in UK universities (EHRC, 2019).

The NUS 'Hidden Marks' report found that one in seven of the women students experienced serious physical or sexual assault, and two thirds verbal or non-verbal harassment whilst at university (NUS, 2011b). Most recently, their 'Sexual Violence in Further Education' report of data from 544 responses to an online survey found that $61 \%$ of men and $78 \%$ of women students had an unwanted sexual experience at least once (NUS, 2019), Brook, a sexual health and wellbeing provider whose online survey of 5649 UK university students found that $53 \%$ had experienced unwanted sexual behaviours from another student (Brook, 2019). Interview and focus group research has suggested that molestation is considered a normal part of a night out for women at university (Phipps and Young, 2013). Systematic review shows that lesbian, gay, bisexual, transgender/transsexual, queer plus (LGBTQ+) students are more likely to 
experience sexual harassment than cisgender heterosexual students (Fenton et al., 2016). A national cross-sectional study of students in 25 UK universities found that $12 \%$ of women and $6 \%$ of men had experienced a forced sexual act. Further findings included: $70 \%$ of women and $40 \%$ of men had been made to feel uncomfortable by remarks with a sexual undertone, half of women and a third of men had been groped, and a third had received unsolicited explicit materials online (Camp et al., 2018). The Brook student survey identified a similar prevalence; $10 \%$ of respondents reported being forced into a sexual act or penetrative sex. This survey also found that whilst nine in ten respondents were confident to say 'no' to unwanted approaches, $16 \%$ of the women and $6 \%$ of the men had been pressured into a sexual act, and $10 \%$ of male and female students had felt obliged to have sex. Notably, whilst $56 \%$ of respondents said they had experienced wolf whistling, touching, being followed, explicit messages, being exposed to sexual conversation, and/or being pressured or forced into a sexual act, only $15 \%$ felt that they had experienced sexual harassment. This four-fold disparity was suggested to be underpinned by lack of education on what constitutes harassment and consent (Brook, 2019). The UK is not alone in this situation. There are initiatives to understand the student experience, and reduce the incidence of sexual assault and harassment in Australia, New Zealand, and the USA universities, using whole campus approaches (Australian Human Rights Commission, AHRC, 2017; Kania and Cale, 2018; Snowden, 2018; Beres et al., 2019; Kettrey and Marx, 2019),

UK universities have attempted to address students' lack of knowledge by running workshops. Most have specifically focused on reducing sexual harassment. The assumption that harassment in this domain results from a lack of understanding about consent means that workshops tend to focus on consent education. There has been little focus on reducing harassment based on race, religion, gender identity, or sexuality (NUS, 2015).

Whilst consent workshops are often favourably received by participants (e.g. NUS, 2015) there is little evidence to suggest they lead to a sustained reduction in harassment over time, and there is some evidence of negative backlash (Camp et al., 2018). A recent review demonstrates 
that increasing knowledge or changing attitudes alone is not sufficient to reduce sexual violence (DeGue et al., 2014). In fact targeting men whose attitudes to sex and women mean that they at higher risk of perpetrating sexual aggression can trigger 'boomerang effects' of hostile resistance, and actually increase unwanted behaviours (Malamuth et al., 2018).

An alternative approach to targeting potential protagonists is to engage the broader university community in training that increases the chances of witnesses, or 'bystanders', stepping up to help by increasing their capacity to intervene, rather than passively ignoring incidents or waiting for someone else to act (Latane and Darley, 1970; Fenton et al., 2016). Bystander interventions focus on the role and responsibility of the community as a whole in the primary prevention of antisocial behaviour. Fenton et al. (2016) propose that bystander programmes should enable a witness to recognise the target behaviours, to interpret incidents as problematic, assume responsibility, and know how best to act. Indeed Kania and Cale (2018) identified failure to recognise situations as having potential for sexual violence as the reasons for Australian students to miss an opportunity to help one another.

There is evidence that university bystander training on US campuses reduces victimisation and perpetration as compared to no-training campuses, and post-training feedback indicates increased knowledge and intention to intervene in sexual violence (Fenton and Mott, 2017; Kettrey and Marx, 2019). There is, however, a lack of evidence for their transference to a UK context (Labhardt et al., 2017). At present, a small-scale evaluation of a Bystander programme by Fenton and Moss (2018) at one university shows promise in reducing acceptance of 'rape myths', i.e. false beliefs that excuse and perpetuate sexual aggression, and in increasing bystander efficacy, readiness to help, and responsibility. The impact on actual bystander behaviour has not yet been assessed (Fenton and Mott, 2018). The evaluation found no evidence of backlash, and the programme seemed acceptable to UK students (Fenton and Mott, 2018). It is possible that these findings can be extended to harassment and hate crime, based on positive outcomes for programmes targeting LGBTQ+ harassment in the US (Dessel et al., 2017). 
However, large cohorts of students will be required to influence university community culture, and it is not known how well US findings will translate to UK university contexts.

A number of UK universities have recently introduced online 'report and support' systems for their students; some encompass harassment whilst others focus on sexual aggression. Whilst Towl and Walker (2019) applaud the "palpable shift" (p. 35) in the sector's recognition of the need to markedly increase reporting rates, how well used these systems will be by victims, witnesses, and victims' friends remains to be seen. Brook (2019) found 75\% of forced penetrative sex and $82 \%$ of forced sexual acts are not reported by student victims. Towl and Walker (2019) suggest that minority groups, including international students, have more barriers to reporting incidents than White, middle class students. University community bystander training might reduce under-reporting by increasing its normality. This might have concomitant changes in the attitudes of potential perpetrators, who are aware of the current very low chance of being sanctioned (Towl and Walker, 2019).

In summary, the extent of harassment, assault, and hate crime behaviours in UK universities suggests that urgent actions are required. Bystander interventions seem promising, but little is known about how they might translate into a UK context, or whether witnesses' relationship to victims affects their propensity to step in. More work is therefore needed to understand bystander behaviours in a UK context, and to go beyond the focus on sexual violence.

\section{Aims}

This study sought to explore UK students' perceptions and capacity to act as prosocial bystanders by intervening in and reporting harassment, assault, and hate crimes, and to challenging and 'calling out' negative attitudes in others. The aims of this study were to understand student:

1. Attitudes to the acceptability of sexual assault, harassment and hate crimes; 
2. Attitudes to intervening in such incidents;

3. Attitudes to reporting incidents;

4. Impact of relationship with the protagonists on intervening and reporting.

\section{METHODS}

A cross sectional, anonymous online survey was delivered using Qualtrics survey software. The survey utilised a mixed methods approach employing attitude and intention scales and openended questions to explore these views. Respondents provided written informed consent. They had the opportunity to enter a prize draw for one of three 'Love to Shop' vouchers as an incentive for completing the survey. British Psychological Society ethical guidance to minimise participant burden and safe guard participants' welfare determined the use of scenarios rather than items about personal experiences. The data were collected between $14^{\text {th }}$ March and $13^{\text {th }}$ June 2018. All study procedures received approval from the institutional ethics committee.

\section{Participants}

Student participants from one UK University were recruited opportunistically through Student Union emails and social media. In all, 312 students started the survey, and 201 submitted their completed responses ( $64.4 \%$ completion rate). There were 152 women $(75.6 \%$ of the sample), 41 men, and five non-binary participants. A further three participants ticked the option 'prefer not to say'. The age range was 18 to $52(94.3 \%$ aged $18-30 ; M$ age 21.9; $S D=5.2)$. One hundred and forty three $(71.1 \%)$ identified as heterosexual; $82 \%$ were students from the UK and most of the sample were White (White British 68.7\%; White Other 13.9\%). The majority (61.8\%) were no religion (Christianity 27.6\%, Islam 3.5\%, Judaism 1.5\%, Sikhism 1.5\%, Buddhism 1.0\%, Hinduism $0.5 \%$, other $2.5 \%$ ). $8.0 \%$ reported an additional learning need and $12.6 \%$ a mental health issue such as anxiety or depression. 
The full survey is available here (Please see "Anonymised survey items" document included with the submission).

Attitudes to the acceptability of sexual assault, harassment and hate crimes

To assess attitudes about the acceptability of specific behaviours that might constitute sexual assault, harassment and hate crimes, six scenarios were developed. They were based on real life incidents reported to the university's Student Union Women's Officer and findings from a previous study (Camp et al., 2018). 'Xenophobia' was witnessing someone saying “you're in England, speak English" to a bus passenger who was conversing on the phone in her native language. 'Homophobia' was witnessing a homophobic comment written on the whiteboard in student accommodation. 'Sexual Harassment' was witnessing a group of students routinely gathering to publicly rate the attractiveness of students who were passing a hall of residence. 'Islamophobia' was witnessing a group of young men calling a bearded Muslim student a terrorist as they walked past him at a bus stop. 'Non-consensual sex tape' was a student filming herself and her partner having sex, without his knowledge or consent and showing it to her friends. 'Non-consensual penetrative sex' was a male student having sex with a female student without her consent when she was extremely drunk. The acceptability of each scenario was rated using one item ( $1=$ not at all acceptable to $7=$ highly acceptable $)$. Cronbach's alpha for the scenario acceptability scores was .70, indicating internal consistency in the responses.

\section{Attitudes to intervening in such incidents}

Five items measured respondents' confidence to proactively intervene if another student appeared to be vulnerable to assault or harassment (not at all confident - very confident on a five point Likert scale; $1=$ not at all confident, 3 = neutral, 5 = highly confident). The items were how confident would you be to go up to and offer help to a student who: looks very upset at a party; appears to be very drunk at a party; is being taken to a bedroom by a group of people at a party; is surrounded by people at a party and looks uncomfortable; and asks for help to get 
home from a party. Cronbach's alpha for these scores was .81, indicating good internal consistency.

Eleven items measured respondents' confidence challenge verbal incidents using the same five point Likert scale. Five items focused on sexual / relationship incidents. They were: how confident would you be to say something to challenge a student who is: making excuses for having forced a person to have sex; making excuses for having had sex with a person who was unable to give full consent; making excuses for using physical force in a relationship; a student saying that rape victims are to blame for the rape; and a student who was verbally abusing their partner. Cronbach's alpha for these scores was .91, indicating excellent internal consistency.

A further six items focused on protected characteristics: They were: imagine you are having a conversation with another student. How confident would you be to challenge them if they are expressing negative views or making an unkind joke about other people because of their: gender reassignment; race; religion or belief; sex or gender; or sexual orientation conversation. Cronbach's alpha for these scores was .95. An open text question invited further comments on confidence to intervene.

\section{Attitudes to reporting incidents}

Respondents were asked to indicate to whom they would report the scenario incidents if it happened to someone else, and if happened to themselves from options including the Police, specialist Victim Support, Sexual Assault and Rape Crisis team (sex without consent scenario only), university student welfare staff, hall wardens, academic staff, friends or family, and would not report. Three items measured likelihood to report incidents they were told about by the victim. Six items measured how likely respondents were to call for expert help from 999, campus security, or pub/club staff if they heard a person calling for help (very unlikely - very likely on a five point Likert scale; 5 = very likely) in student accommodation; on campus; at a party; in a pub or club; on public transport; in a public space. Six items measured likelihood to 
report disability, gender reassignment, race, religious belief, a sex or gender; or sexual orientation harassment they witnessed. The items were someone tells you that: they have been sexually assaulted; they are being abused; and they are being harassed. An open text question invited further comments on reporting.

Impact of relationship with the protagonists on intervening and reporting

Respondents were asked to rate the overall likelihood of trying to help a student at a party if they were their friend; someone they recognised; and someone they did not recognise, on a sliding scale from 0 - 100 ( 0 = very unlikely, 100 = very likely). They were also asked to rate the likelihood of challenging perpetrators of the 11 verbal incidents (making excuses, victim blaming, verbal abuse, unkind comments/jokes) on the same dimensions. Eighteen items measured whether the respondent would report the situation in the six scenarios (Yes, Maybe, No) if the scenario happened to them, or if the victim was a friend or a stranger.

Demographic information including age, gender, ethnicity; sexual orientation, religion; full or part time status; campus; undergraduate year of study or post-graduate degree; UK, EU or nonEU student; and learning difficulty and disabilities.

The survey concluded with a debrief page with information about university and external support services for anyone affected by any of the issues raised in the survey.

Analysis

Descriptive and inferential statistics for the quantitative survey data were created in SPSS 25 (IBM, 2017). ANOVA were used to identify whether attitudes differed between the scenarios and according to the closeness of relationship to the protagonists. The open text data were analysed using thematic analysis employing the six phases outlined by Braun and Clarke (2006). 
The data were analysed inductively, guided by the aims to understand student attitudes to intervening and reporting, and deductively to recognise further aspects of student experience. The analysis phase started with Author 1 familiarising themselves with the data by reading and making notes. The responses were coded line by line, dividing the text into meaningful units. This process resulted in 38 separate codes. During the search for themes, some codes were combined, and others were discarded as not relevant or not representative of the data. An initial set of themes was generated using a thematic map, and Authors 1 and 6 met to discuss their meaning and interpretation. Once the themes had been generated, named and agreed upon, the data were revisited to ensure that the final set of themes and sub-themes represented the data set. Two inductive and two deductive themes were identified. They described the students' experiences and reflections on harassment and assault, providing depth and context to the quantitative responses.

\section{RESULTS}

\section{Attitudes to the acceptability of sexual assault, harassment and hate crimes}

Almost all the respondents rated the six scenarios as unacceptable $(M=1.32$, SD $=0.46)$. Nonconsensual penetrative sex was the most unacceptable (100\% scored as 1-3); followed by Nonconsensual sex tape (99.5\%), Islamophobia (99\%), Xenophobia (98\%), Sexual Harassment (94\%), and Homophobia (91.5\%). ANOVA showed statistically significant differences between the acceptability of the scenarios $(F(3.23,639.96)=38.05, p<.001)$, with a nominal effect size (partial eta squared .16). Post-hoc tests showed that the sexual incidents were least acceptable, and the Islamophobia scenario was less acceptable than the Xenophobia, Sexual Harassment, and Homophobia scenarios $(p<.001)$.

\section{Attitudes to intervening in incidents}

The majority of respondents indicated that they were confident or highly confident ('confident' hereafter) to proactively intervene if another student appeared to be vulnerable to assault or 
harassment at a party, $(M=3.96, \mathrm{SD}=0.74)$. Nearly all $(90 \%)$ were confident to respond to a direct request from another student for help to get home from a party. Around three quarters were confident to proactively approach and offer to help other students (looked very upset: 75.6\%; surrounding by a group and appeared uncomfortable: $72.2 \%$; being taken to a bedroom by a group: $68.1 \%$ ); $15 \%$ were neutral about offering help in these situations. Sixty percent were confident to approach and offer to help a student who appeared to be very drunk at a party, whilst a quarter of respondents were neutral about this. There was a highly significant difference between confidence to help in the different contexts $(F(3.42,680.43)=29.82, p$ $<.001$ ), although the effect size was small (partial eta squared $=.13$ ). Post hoc tests indicated that students were significantly more confident to respond to being asked for help to get home than to intervene in the other contexts, and to offer to help someone who was upset rather than very drunk $(p<.001)$.

Average confidence to challenge sexual comments was high $(M=4.29, S D=0.81)$. Nearly all (90.5\%) indicated high confidence to challenge a student who expressed 'victim blaming' views about rape victims during conversation. Approaching 90\% would verbally challenge someone making excuses for forcing someone to have sex (89.6\%), for having sex with someone without their full consent (89.1\%), or for using physical force in a relationship (87.6\%). Three quarters (75.6\%) were confident to challenge someone who was verbally abusing their partner. There was as a highly significant difference between confidence to intervene in the different types of incidents $(F(3.48,692.75)=15.07, p<.001)$, although the effect size was nominal (partial eta squared $=.07)$. Post hoc tests showed that students were significantly less confident to intervene in verbal partner abuse $(p<.001)$. This indicates that the students were less confident to intervene in a face-to-face situation between a couple than in derogatory comments about absent people.

Most respondents reported being confident to challenge negative views or unkind jokes about race $(91.5 \%)$, disability $(88.1 \%)$, sexual orientation $(88.6 \%)$, sex or gender $(85.6 \%)$, religion or 
belief (84.6\%), or gender reassignment (82.1\%). Average confidence to challenge protected characteristic comments was high $(\mathrm{M}=4.23, \mathrm{SD}=0.76)$. There was as a highly significant difference in confidence to challenge the different incidents $(F(4.65,882.75)=4.65, p=.001)$, although the effect size was nominal (partial eta squared $=.02$ ). Post hoc tests showed that students were significantly more confident to call out comments about race and sexual orientation than gender reassignment, and about race than religion $(p<.05)$, which indicates that the students might find it easier to challenge some types of comments.

\section{Attitudes to reporting incidents}

Table 1 shows that the majority of respondents indicated that they would report the scenario incidents if they happened to someone else. The Non-consensual penetrative sex and the Nonconsensual sex tape scenarios were most likely to be reported to the Police and specialist support services. Generally, more would tell friends and family than university welfare staff. Hall wardens were more likely to be told about hall-based incidents than those that happened elsewhere. Some respondents indicated that they would not report the incidents. Of note is that fewer respondents said they would seek support from the Police if the Non-consensual sex tape and Non-consensual penetrative sex incidents happened to them $(36.3 \%, 42.3 \%)$. However, more (60\%) said they would seek support from their friends and family if they were the victim in these situations.

\section{Insert Table1}

The majority of students indicated that they were highly likely or likely (hereafter 'likely') to contact 999, campus security, or pub/club staff if they heard a person calling for help in their student accommodation (83.8\%), on campus (78.0\%), at a party (76.3\%), in a pub or club (75.9\%), on public transport (74.6\%), or in a public space (69.8\%). Fewer were neutral about contacting experts help for accommodation incidents than for the other situations $(11.7 \% \mathrm{v}$. 15 $17 \%$ ). No more than $10 \%$ indicated that would be unlikely or very unlikely to contact security. 
Whilst there was a significant difference in likelihood to call for help in the different situations, $(F(7.72,680.31)=7.72, p<.001)$, the effect size was nominal (partial eta squared $=.037)$. Posthoc tests indicated that students were only more likely to call for help if the incident was in their accommodation $(p<.05)$.

Most indicated that they would report harassment they witnessed (race: 75.1\%; disability: 74.5\%; sex/gender: 73.6\%; sexual orientation: 72.1\%; religion/belief: 69.6\%; gender reassignment: 69.5\%). There were highly significant differences between likelihood to report different types of witnessed harassment $(F(3.90,772.11=3.95, p=.004)$, but the effect size was nominal (partial eta squared $=.02$ ). Post-hoc tests indicated that students were significantly more likely to report racial than religion/belief and gender reassignment based harassment $(p<.05)$

Most of the respondents indicated that they were likely to report incidents they were told about by a victim (sexually assaulted $78.6 \%$; being abused $82.6 \%$; being harassed $73.1 \%$ ). There were highly significant differences between likelihood to report in these circumstances $(F(1.89$, $378.86=13.92, p<.001$ ) (partial eta squared $=.065$ ), and post-hoc tests indicated that students were significantly less likely to report accounts of harassment $(p<.05)$.

\section{Impact of relationship with the protagonists on intervening and reporting.}

Respondents indicated that they were more likely to try to help a student at a party, on the scale of 1-100, if they were a friend $(M=93.78, S D=15.19)$ than someone they recognised $(M=$ $85.18, \mathrm{SD}=18.66)$ or a stranger $(\mathrm{M}=73.20, \mathrm{SD}=25.04)$. The differences were highly significant $(F(1.48,290.96=125.63, p<.001)$ with moderate effect size (partial eta squared $=.389)$; posthoc tests showed significant differences between each level of relationship ( $p<.001)$.

Respondents indicated that they were more likely to challenge friends ( $M=88.15, \mathrm{SD}=18.79)$ than acquaintances $(M=75.20, S D=23.03)$ or strangers $(M=65.48, S D=27.55)$ who made excuses or blamed victims for sexual assault during conversation, or verbally abused their 
partner in their presence. The differences were highly significant $(F(1.65,324.80=87.18, p$ $<.001$ ) with moderate effect size (partial eta squared $=.307$ ). More respondents would also be likely to challenge friends who expressed negative views or unkind jokes about protected characteristics $(M=84.38, S D=23.11)$ than acquaintances $(M=74.93, S D=22.19)$ and strangers (M 63.38, $\mathrm{SD}=29.07)$. The differences were highly significant $(F(1.49,292.28=74.92, p<.001)$ with small-moderate effect size (partial eta squared $=.277$ ). Post-hoc comparisons showed significantly differences by relationship in both cases $(p<.001)$. This means that, whilst most students would step up to help another and would call out disparaging comments, closeness of relationship had an effect on likelihood to prosocially intervene.

T-tests showed that respondents were significantly more likely to report the scenario incidents if the victim was their friend than a stranger, and the effect sizes were generally moderate to large, as shown in Table 2. However, scores of 2 represent "maybe" responses, so only the Nonconsensual penetrative sex scenario was likely to be reported irrespective of the witness's relationship with the victim.

\section{Insert Table2}

The majority (71.6\%) of respondents indicated that they would report the Non-consensual penetrative sex scenario if it happened to them; only 5.5\% indicated that they would not report it. Most (65.5\%) would report the Non-consensual sex tape scenario if they were the victim, but less than half would report the Islamophobia comment (45.2\%), being scored for attractiveness (41\%), and a quarter would report the Xenophobia and Homophobia situations (24.5\%), whereas half would not report them.

\section{Open text data}

Eighty-five students provided 264 open text responses. Four themes were identified (Table 3). Barriers to Intervening and Barriers to Reporting pertained to the research aims about attitudes to intervening and reporting. Inductive themes were Perception of Perpetrators, which 
encapsulated student perceptions of the type of people who harass and assault others, and the Need for University Community Education, which expresses student views on how to address lack of understanding about harassment and consent, reporting mechanisms, and how to support peers.

Insert Table 3

The theme Barriers to intervening encapsulates factors that would deter students from stepping in. Barriers included perceived risks and norms about harassment.

\section{Risks of intervening}

Fourteen students expressed caution about intervening, for reasons of self-preservation or being unsure if it would be helpful to "interfere" in others' relationships or if someone "just wants to be left alone". Reservations included "I would be cautious about offering someone I didn't know a lift home but would be happy to help them find a safe way home". Others expressed concerns about backlash if they challenged a group of strangers, for example:

"When it is a large group of people and you are by yourself challenging them is difficult and potentially dangerous. When confronting a stranger again you are putting yourself in danger if they really hate the people they are abusing, and therefore it is important to take your welfare into consideration." (Woman)

The only indicator of the Bystander Effect was that two female respondents mentioned that they would wait to see "if other people call (for expert help) first" or take intervene: "If there's lots of people around I would probably be more likely to expect someone else to take action".

\section{Norms about harassment}

Nine students commented on their normalised perception of harassment: "I naturally perceive harassment as fairly minor and something that should be brushed off", and "we all know being at uni is a bit of a cattle market". One female student discounted verbal harassment: "I personally 
believe that, though heinous, the actions are merely speech and shouldn't be harmful'. One man expressed the potential tension between valuing freedom of speech and sensitivity to not offending people: "There is a lack of freedom of speech and people are too afraid to make jokes now because people think they are promoting hate speech".

The Barriers to reporting theme describes reasons why respondents would not report incidents on other people's behalf, including the best interests of themselves and victims, and beliefs about what should be reported.

Respecting the victim's decision

Thirty-eight responses expressed how important it is to respect an assault victim's wishes about reporting, and that they should be the judge of whether an incident was harmful or not. A male student also commented that offering support to report assault was more important than interceding:

"I would 100\% provide support and be there for them and fully support their wishes if they wanted me to reported it for them, but I'm not sure I would without them asking me to".

\section{Reporting backlash}

Whilst one student said they had called the Police when they heard people calling for help, and another that they had reported racial harassment of peers in their accommodation, more commented on barriers to reporting. Fourteen people explained that fear of consequences for self, such as loss of "social standing, as being ostracised by your peers is a huge fear of many university students". Loss of anonymity, "fear of making a situation worse", and "backlash from others" can deter victims and witnesses from reporting incidents. Some expressed the view that rape victims "remain quiet" and "wouldn't want to draw attention to the issue", perhaps because, as one man put it, "rape victims are put through so much BS and might not even see their rapist convicted. Reporting is still stigmatised". This indicates a belief that the consequences of reporting might be worse for victims than perpetrators. Moreover, the opinion that "people are 
far less likely to report something if they do not believe they will be taken seriously" indicates lack of faith in the reporting system.

\section{Cultural norms about not reporting abuse/seeking support}

This lack of faith, in addition to cultural norms about not reporting incidents was mentioned by two international students. One commented that the "acceptability of abuse either physical, mental or sexual" of women in her home country, where "females are suppressed from expressing their views" was impacting her peers' tendency to "shy away from reporting incidences" and "thinking that nothing will happen even if they.... approach the services provided in the university or in the UK". Another said the costs of reporting were greater than the benefits: "in my native country at least, I would be considered a nuisance and traumatised myself if reporting minor cases".

\section{Experience of not / reporting incidents}

Two women described the negative impact of reporting an incident. One, who had reported disability harassment, was discouraged from doing so again because "there hasn't been much impetus to change and nothing happened". She went on to say "this has made me less able to make reports". Reporting an incident had led another to have to move, whilst the perpetrator was unpunished:

"I was threatened with sexual assault by my house mate and I did not know where to report it so I told the housing officer. As there was no evidence I was made to move and he remained living at the property".

Five people said they had not reported being harassed, sexually assaulted or raped. One thought that if she were to make a complaint about homophobia, it would be dismissed as "a joke or a bit of banter". One explained that she did not report an assault because "I had no idea who I should go to for help or to report the assault". Another felt that being drunk would undermine her 
credibility: "seeing as I was very intoxicated, I doubted that anyone would take me seriously". Three others said that they had been sexually assaulted, and did not mention reporting.

Perceived seriousness of the event.

Eighteen students explained that context would determine whether they reported witnessed incidents. Concern about raising false alarms might deter them from contacting the Police or other experts because "people shout all sorts of things when messing around". They explained that judgement of the situation based on "how they were calling for help, i.e. the tone of voice etc." would be important "to be able to determine how urgent/dangerous it is". Several said that they would regard frequent homophobic or xenophobic harassment as more serious than one-off incidents, and that it was important to discern between rudeness or joking and "malicious intent".

The theme Perception of perpetrators focuses on student perception of the type of people who harass and assault others. Thirteen respondents commented on their opinion of the type of people who harass and assault others. The stereotype of perpetrators of assault and hate crimes as "idiots (who) think they have a sense of entitlement" and "over privileged students who were often educated in boarding schools or gender divided schools and in turn lack awareness/decency regarding these issues" suggests that students regard attitudes acquired at school as a key factor in university behaviour. Several mentioned the negative impact, for example: "the perpetrators of sexual harassment and assault... are hindering the university experience for others" and that unwanted behaviours can make students feel "unsafe".

Some students commented on their awareness of drink spiking and sexual assault in clubs, with one woman saying "it's very common for girls to be sexually assaulted in clubs". Others expressed that groups of male students could negatively affect others' experience of social events: "groups often make club nights etc. daunting unsafe places for those who are not with them", and that harassment and sexual assault was "acceptable" within those "powerful" groups. One suggested that fear of backlash about reporting such people, and concomitant lack of consequences, could 
reinforce the perceived acceptability of unwanted behaviours in perpetrators and their social groups.

One posed the question "so how do you stop it? How do you educate people so it never reaches that point?" Seventeen students suggested that the university could do more, both in terms of improving the physical safety of students with better lighting on dark footpaths, and not allowing club nights that perpetuated discriminatory attitudes, such as "'Arab Prince Party' and then lots of white people marching about in Muslim dress".

The theme Need for university community education focuses on students' calls for action to educate the university community about what constitutes consent, and how to report and support others. There were 50 comments about the need to improve education about consent and behaviour behaviours across the university community. Whilst one said "Males in particular seen to not understand what constitutes rape or sexual assault and when one cannot consent", one also felt that women were under-informed:

"Educating students on these issues is also important - not only for lads to understand - but for girls and women who are not sure whether what has happened to them is 'OK', or what to do about it (where to go, how to go about getting help, who to tell)." (Woman)

However, both these examples portray men as the perpetrators and women as the likely victims, which is an unhelpful stereotype.

Twenty-one people mentioned the need for consent training, such as: "Prevention, by educating people about what is and is not acceptable behaviour will help", and would address "false sense of entitlement" and the situations that occur because "some people are still unaware of what constitutes harassment and sexual assault".

Twenty people called for education about reporting, Several felt that there was a lack of knowledge about how and to whom to report witnessed or experienced incidents, and that 
students might be "too shy" to do this face to face. One suggested that this could be overcome by "normalising the process of reporting, and making this info easily and widely available".

Seven mentioned need for information on how to support others, for example "how to start and have difficult conversations with friends if you're worried about them", and "the help lines or support that is on offer needs to be made more obvious clear and available to students".

Some suggested email and posters as ways of conveying information about what constitutes unwanted behaviours and how to report them. Another suggestion was to include information in student handbooks, and that "this needs explicit examples of the kinds of behaviours that are not acceptable, not just generic 'respect others' guidelines". Others suggested information sessions or mandatory consent training, particularly on arrival at university. There were also mentions of the need for regular staff training, and increasing university community empathy for minorities within institutions that "lack diversity".

\section{$\underline{\text { Discussion }}$}

This study aimed to explore students' perceptions and capacity to act as prosocial bystanders by intervening in and reporting sexual assault, harassment and hate crimes, and by challenging and 'calling out' negative attitudes in others. Students regarded sexual assault, harassment, and hate crimes as unacceptable, particularly non-consensual sexual behaviours. The majority of students had positive attitudes to stepping in to physically help their peers, although this was attenuated if the vulnerable person was very drunk. Some respondents expressed reservations about approaching people who might wish to be left alone, and caution about putting oneself in a vulnerable position, especially if trying to stop the behaviour of hostile groups. Only two respondents said they would stand by and see if someone else intervened, thus exhibiting the Bystander Effect described by Latane and Darley (1970).

The description of university as a cattle market acknowledges that students might be actively seeking sexual partners. Whether this underpins the acceptance of some sexual harassment as 
part of university life, also found by Phipps and Young (2013), was not determined by the current study, but the Brook (2019) study showed considerable disparity between what students and researchers classify as sexual assault. Dismissal or acceptance of harassment by or of any group of students, such as by women on a night out (Phipps and Young, 2013), can only undermine any tendency to intervene in and report incidents. Whatever underpins acceptance, comments from international students about their inculcation into not objecting to or reporting harassment prior to coming to study in the UK indicate how important it is to consider diversity when designing interventions, emphasised by Towl and Walker (2019). Bystander training must therefore address university community complicit attitudes to harassment of themselves and of any group of students, whilst avoiding the potential backlash from targeting potential offenders (Camp et al., 2018; Malamuth et al., 2018). Indeed Towl and Walker (2019, p. 28) identify cultural change as the "the most substantive part of the discussion on prevention".

Respondents were confident to call out discriminatory comments and derogatory jokes than to intervene in physical situations between protagonists, although they were more cautious about interfering in verbal abuse in relationships, again perhaps for fear of backlash. Greater confidence to call out remarks about race or sexual orientation than gender reassignment or religion might suggest that it is easier to challenge views on these characteristics. However, the effect size was nominal, and students were consistently confident about calling out prejudiced views. Given that $16 \%$ of students feel they have been the victim of hate related incidents (NUS, 2012), and the high proportion of students who are made to feel uncomfortable by sexual comments (Camp et al., 2018), it is encouraging that many students feel comfortable to call out their peers' views. However, there was indication that some do not regard verbal harassment as harmful, and that fear of offending constrains freedom of speech. Such attitudes might perpetuate and even exacerbate verbal harassment and discrimination, if the potential backlash from targeting consent training at high risk men (Malamuth et al., 2018) might also manifest as deliberate comments in the guise of freedom of speech. 
The majority had positive attitudes to reporting incidents. They were generally more likely to reach out to their informal friends and family support network, although they would report sexual incidents to the authorities. However, the proportion who said they would report the non-consensual penetrative sex scenario on their own behalf (42.3\%) was much higher than the $25 \%$ reporting rate amongst UK university students found by the 2019 Brook survey()0. This might mean that the responses about the likelihood to report witnessed incidents were overstated, and although several respondents said that they had not reported being assaulted or raped, no-one said they had reported this.

Reasons for not reporting on someone else's behalf included privileging the victim's wishes about reporting incidents, and that supporting was more important than reporting. Thus, although students were willing to report witnessed incidents, they might prioritise offering caring support. Similarly to intervening, there was caution about backlash of reporting for themselves and victims. These fears, along with the comment that reporting rape is stigmatised, should be addressed in bystander training (Fenton and Mott, 2018). However, no matter how effective training about reporting is, the Crown Prosecution Service (CPS) reveals very low prosecution rates for sexual assaults and rapes in the UK (4\%, 1.9\%) (CPS, 2018).

Most respondents were likely to call the emergency services or local security staff if they heard someone calling for help, particularly if it happened in their accommodation. This might indicate that social and/or physical proximity could be factors in getting outside help if someone seems to be in trouble. Most would also report harassment they witnessed, particularly racial harassment. The differences between likelihood to report racial and gender reassignment or belief-based incidents might indicate differing acceptability of these offenses, or not knowing that some types of events constitute hate crimes. Barriers to reporting such incidents included concerns about raising false alarms, and whether the harassment was malicious, which suggests they might be more focused on the perpetrators' intention than the victims' subjective experience. 
The relationship of the witness to the protagonists affected attitudes to intervening and reporting. Respondents were more likely to intervene on behalf of and call out friends than acquaintances or strangers. Similarly, respondents were more likely to report the scenario incidents on a behalf of a friend than a stranger. This indicates that, whilst most students would intervene with each other, they were more likely to do so when relationships were closer, also found by Kania and Cale's (2018) in Australian students . It may be that caring about a friend's wellbeing and safety not only increases the likelihood of intervening, but also outweighs concerns about potential backlash Lower appraisal of potential backlash might also increase the likelihood of challenging a friend, and friends' opinions about sexual assault and protected characteristics might be considered more important than other peoples' contentious attitudes. However, the percentage who indicated they would report the Non-consensual penetrative sex scenario if it happened to them far exceeded the proportion of rapes that victims reported in the 2019 Brook study (71.6\% v 25\%)(0). However, the scores indicated that, although the scenarios were rated as highly unacceptable, most respondents indicated 'maybe' as to whether they would report the Xenophobia, Homophobia, and Sexual Harassment scenarios, irrespective of their relationship with the victim. They tended to be more likely to respond 'yes' if the victim of the Islamophobia or sexual scenarios was their friend. These data suggest that although students might have the knowledge and attitude to know that these behaviours are problematic, they may lack the attitude or capacity to report the events, thus not intervening in potential future incidents.

Students had negative perceptions of people who perpetrate harassment, assault and hate crime; they were described as entitled, over privileged, and powerful, particularly when in groups. Sexual assault was pervasive in nightclubs, and perpetrators' behaviour contributed to others feeling unsafe, with negative impact on university life. Whilst there was some acknowledgement that these behaviours might be due to ignorance rather than malicious intent, there were calls to educate the university community about consent, reporting, and supporting. This might affect university norms about reporting, with impact on the attitudes of potential 
perpetrators (Towl and Walker, 2019). All the mentions of perpetrators pertained to men, but there was acknowledgement that women also need to know more about what constitutes assault and consent. Various suggestions were made as to how to disseminate information, including in writing and via courses. However, no one asked for training in how to intervene in incidents, suggesting that they put the responsibility for change on protagonists.

\section{Implications}

This study demonstrates that students regard sexual assault, harassment, and hate crime as unacceptable, and that they generally feel confident to prosocially intervene and to report incidents. These attitudes should mean that bystander training would be acceptable in university contexts, and that report and support systems would be acceptable to and utilised by students. We await information on the take up of several new UK university report and support tools and whether the emergent roll out of consent training in UK universities makes a difference to prevalence. Currently, UK university bystander training initiatives is constrained to one programme that focuses on sexual incidents (Fenton and Mott, 2018). Student opinion as to whether hate crime should be an integrated element or the focus of a separate programme should be evaluated. Action to develop and implement such programmes might largely depend on UK university managers and NUS advocates.

Importantly, despite positive attitudes to stepping in, students expressed barriers to intervening and reporting. That the students appeared to place the onus for change on protagonists, rather than asking to be trained to intervene suggests that there is some way to go before the concept of being a proactive bystander becomes a norm. Concerns about disempowering the victim by reporting without their consent illustrates sensitivity to their peers' autonomy. Whether increased bystander reports would result in changed prosecution rates is unknown.

Whilst this is a complex problem, leveraging the attitudes, knowledge, and capabilities of protagonists and witnesses should have potential to reduce the number of incidents, and 
reporting should increase, enabling investigation and appropriate action against perpetrators. University community rejection of these behaviours has potential to create a shift in the normalisation of unwanted behaviours. Delivering bystander programmes as whole university community training should ameliorate the chance of backlash from high risk groups identified by Malamuth et al (2018). Any subsequent increase in intervention, reporting, and prosecution might deter potential perpetrators.

The reported caveats about intervening, reporting, and getting expert help in cases where intervention does not seem to be safe for either the witness or the victim should be considered when designing bystander training. It is important to address the potential for backlash from intervening or reporting within the programme, and to include strategies for what to do if witness intervention appears to be unsafe for witnesses and/or victims. Training should also target inculcated acceptance of prejudiced attitudes and the incidents that arise from them, particularly for minority groups. Whether bystander training programmes should be tailored to the needs of minority groups as well as those of the whole university community remains to be seen.

\section{Future steps}

It is important to understand the complexities in UK university student witnesses' capabilities and barriers to prosocially intervening in and reporting assault, harassment, and hate crime incidents. Applying a behaviour change framework would strengthen the development and evaluation of an evidence and theory based bystander training programme for university communities, in accordance with Medical Research Council guidance (MRC, 2008). Behaviour change analysis, such as that described in the Behaviour Change Wheel (Michie et al., 2014), may be useful.

\section{Limitations}


This was a cross sectional survey conducted at one UK University, so the data might not reflect other students' attitudes. The 201 participants are a very small subsample of the UK's 2.3 million students (Higher Education Statistics Agency, HESA, 2019). The sample was reasonably representative of ethnicity ( $83 \%$ v 78\% White) and UK nationality (82\% v 80\%) (HESA, 2019). There were more women ( $76 \%$ v 57\%), and students aged 30 and under ( $94 \%$ v $80 \%)$ than in UK universities. Fewer respondents reported a disability (8 \% v 12\% nationally) (HESA, 2019). Fewer identified as heterosexual than UK 16-24 year olds (71\% v 90\%) (Office for National Statistics, ONS, 2019). More of UK 16-24 year olds report no religion (71\%) compared 62\% of the sample (Curtice et al., 2019). As such, the outcomes might not generalise to UK or other country's students.

The open text caveats to the Likert scale data indicate that respondents may have overstated their confidence and likelihood to intervene in incidents, and this response bias may explain the disparities between the data and known reporting rates for sexual assault. The study did not examine what, if anything, respondents would do if they felt unable to intervene, and it cannot be assumed that they would call for expert help in such situations, despite the high scores on these measures.

The Student Union's (SU) 'student voice' and safety roles mean that SU emails and social media were an appropriate conduit for disseminating the survey. However, reach would have been constrained to those who engage with such communications.

\section{Conclusion}

Students consider sexual assault, harassment, and hate crime to be unacceptable. They have a negative view of perpetrators and suggest that university community consent, reporting, and supporting training is required. Students have positive attitudes to prosocially intervening in and reporting such incidents. This can be hindered by concerns about the consequences, beliefs about whether incidents should be reported and if the system will be effective, and wanting to be sure that the act was malicious or was construed as serious by the victim. Given the positive 
attitudes towards helping other students, whether they are friends, acquaintances, or strangers, the university student community should be amenable to bystander training. Tackling the complexities of prosocial intervention in the university community will likely require a complex intervention, but programmes that capitalise on students' positive attitudes towards helping each other should have potential to reduce sexual assault, harassment, and hate crime in the university community, and to increase reporting of such incidents.

\section{REFERENCES}

AHRC (2017) Change The Course: National Report on Sexual Assault and Sexual Harassment at Australian Universities [Online]. Available at: https://www.humanrights.gov.au/our-work/sexdiscrimination/publications/change-course-national-report-sexual-assault-and-sexual. Beres, M. A., Treharne, G. J. and Stojanov, Z. (2019) 'A whole campus approach to sexual violence: the University of Otago Model', Journal of Higher Education Policy and Management. Braun, V. and Clarke, V. (2006) 'Using thematic analysis in psychology', Qualitative Research in Psychology, 3(2), pp. 77-101.

Brook (2019) Sexual Violence and Harassment in UK Universities. Available at:

https://www.brook.org.uk/data/Brook DigIN summary report2.pdf.

Camp, S. J., Sherlock-Smith, A. C. and Davies, E. L. (2018) 'Awareness and support: students' views about the prevention of sexual assault on UK campuses', Health Education.

CPS (2018) Violence Against Women and Girls. [Online]. Available at:

https://www.cps.gov.uk/publication/violence-against-women-and-girls.

Curtice, J., Clery, E., Perry, J., M., P. and Rahim, N. (2019) British Social Attitudes: Religion;

Identity, behaviour and belief over two decades. [Online]. Available at:

http://www.bsa.natcen.ac.uk/media/39293/1 bsa36 religion.pdf.

DeGue, S., Valle, L. A., Holt, M. K., Massetti, G. M., Matjasko, J. L. and Tharp, A. T. (2014) 'A

systematic review of primary prevention strategies for sexual violence perpetration', Aggression and Violent Behaviour, 19(4), pp. 346-362.

Dessel, A. B., Goodman, K. D. and Woodford, M. R. (2017) 'LGBT discrimination on campus and heterosexual bystanders: Understanding intentions to intervene', Journal of Diversity in Higher Education, , 10(2), pp. 101-116

EHRC (2019) Racial harassment in higher education: our inquiry. Available at: https://www.equalityhumanrights.com/en/inquiries-and-investigations/racial-harassmenthigher-education-our-inquiry\#respond (Accessed: 28/03/19).

Fenton, R. A. and Mott, H. L. (2017) 'The Bystander Approach to Violence Prevention: Considerations for Implementation in Europe', Psychology of Violence, 7(3), pp. 450-458. Fenton, R. A. and Mott, H. L. (2018) 'Evaluation of the Intervention Initiative: A Bystander Intervention Program to Prevent Violence Against Women in Universities', Violence and Victims, $33(4)$.

Fenton, R. A., Mott, H. L., McCartan, K. and Rumney, P. N. S. (2016) A review of evidence for bystander intervention to prevent sexual and domestic violence in universities. London. [Online]. Available at: http://eprints.uwe.ac.uk/28656/1/PHE PublishedLitReviewApr2016.pdf (Accessed: 2nd August 2017). HESA (2019) Higher Education Student Statistics: UK, 2017/18 - Student numbers and characteristics. [Online]. Available at: https://www.hesa.ac.uk/news/17-01-2019/sb252higher-education-student-statistics/numbers. IBM (2017) IBM SPSS Statistics for Windows, Version 25.0 [Computer program]. (Accessed. 
Kania, R. and Cale, J. (2018) 'Preventing Sexual Violence Through Bystander Intervention: Attitudes, Behaviors, Missed Opportunities, and Barriers to Intervention Among Australian University Students', Journal of Interpersonal Violence, p. 886260518764395.

Kettrey, H. H. and Marx, R. A. (2019) 'The Effects of Bystander Programs on the Prevention of Sexual Assault across the College Years: A Systematic Review and Meta-analysis', Journal of Youth and Adolescence, 48(2), pp. 212-227.

Labhardt, D., Holdsworth, E., Brown, S. and Howat, D. (2017) 'You see but you do not observe: A review of bystander intervention and sexual assault on university campuses', Aggression and Violent Behavior, 35, pp. 13-25.

Latane, B. and Darley, J. M. (1970) The Unresponsive Bystander: Why Doesn't He Help? New York: Appleton-Century Crofts.

Malamuth, N. M., Huppin, M. and Linz, D. (2018) 'Sexual assault interventions may be doing more harm than good with high-risk males', Aggression and Violent Behavior, 41, pp. 20-24. Michie, S., Atkins, L. and West, R. (2014) The Behaviour Change Wheel: A guide to designing interventions. London: Silverback Publishing.

MRC (2008) Developing and evaluating complex interventions: new guidance (15/12/2011). [Online]. Available at: http://www.mrc.ac.uk/documents/pdf/complex-interventionsguidance/.

NUS (2011a) Hate Crime Interim Report, Exploring students' understanding, awareness and experiences of hate incidents. Available at:

https://www.nus.org.uk/PageFiles/12238/NUS HateCrimeReport web.pdf.

NUS (2011b) Hidden Marks: A study of women's experiences of harassment, stalking, violence and sexual assault (2nd edition). Available at:

https://www.nus.org.uk/PageFiles/12238/NUS hidden marks report 2nd edition web.pdf (Accessed: 6th July).

NUS (2012) No place for Hate, Hate crimes and incidents in further and higher education: religion or belief. Available at:

https://www.nus.org.uk/PageFiles/12238/2012 NUS No Place for Hate Religion Belief.pdf.

NUS (2015) I heart consent pilot report. [Online]. Available at:

https://www.nusconnect.org.uk/resources/i-heart-consent-pilot-report.

NUS (2019) Sexual Violence in Further Education. [Online]. Available at:

https://www.nusconnect.org.uk/resources/sexual-violence-in-further-education-report.

ONS (2019) Sexual orientation, UK: 2017: Experimental statistics on sexual orientation in the UK in 2017 by region, sex, age, marital status, ethnicity and socio-economic classification. [Online].

Available at:

https://www.ons.gov.uk/peoplepopulationandcommunity/culturalidentity/sexuality/bulletins /sexualidentityuk/2017.

Phipps, A. and Young, I. (2013) That's what she said: Women students' experiences of 'lad culture' in higher education. London. [Online]. Available at:

https://www.nusconnect.org.uk/resources/thats-what-she-said-full-report.

Snowden, C. R. (2018) 'Sexual harassment and assault on campus: What can Aotearoa New Zealand learn from Australia's 'Respect. Now. Always.' initiative', Women's Studies Journal, 32(1/2), pp. 73-80.

Towl, G. and Walker, T. (2019) Tackling Sexual Violence at Universities: An International Perspective. UK: Routledge. 
UK university student attitudes to intervening in and reporting assault and harassment

Table 1 To whom witnesses would report the scenario incidents

\begin{tabular}{lcccccc}
\hline $\begin{array}{l}\text { Report } \\
\text { incident to: }\end{array}$ & $\begin{array}{c}\text { Xenophobia, } \\
\%\end{array}$ & $\begin{array}{c}\text { Homophobia, } \\
\%\end{array}$ & $\begin{array}{c}\text { Sexual } \\
\text { Harassment, } \\
\%\end{array}$ & $\begin{array}{c}\text { Islamophobia, } \\
\%\end{array}$ & $\begin{array}{c}\text { Non- } \\
\text { consensual } \\
\text { sex tape, } \%\end{array}$ & $\begin{array}{c}\text { Non- } \\
\text { consensual } \\
\text { penetrative } \\
\text { sex, } \%\end{array}$ \\
\hline $\begin{array}{l}\text { Police } \\
\text { Victim }\end{array}$ & 8.0 & 2.0 & 3.5 & 27.9 & 53.2 & 65.2 \\
$\begin{array}{l}\text { Support } \\
\text { Sexual }\end{array}$ & 10.0 & 6.0 & 4.0 & 15.9 & 19.9 & 21.9 \\
$\begin{array}{l}\text { Assault and } \\
\text { Rape Crisis }\end{array}$ & & & & & & \\
$\begin{array}{l}\text { University } \\
\begin{array}{l}\text { Welfare } \\
\text { Hall }\end{array}\end{array}$ & 30.8 & 34.3 & 35.3 & 42.3 & 35.8 & 39.8 \\
$\begin{array}{l}\text { Wardens } \\
\text { Academic }\end{array}$ & 7.0 & 37.8 & 52.7 & 9.5 & 23.9 & 24.4 \\
staff & 5.5 & 6.0 & 8.0 & 11.9 & 6.5 & 8.0 \\
$\begin{array}{l}\text { Friends or } \\
\text { family }\end{array}$ & 34.8 & 34.3 & 37.8 & 41.3 & 36.3 & 42.3 \\
$\begin{array}{l}\text { Would not } \\
\text { report }\end{array}$ & 33.9 & 25.4 & 19.9 & 12.9 & 7.5 & 3.5 \\
\hline
\end{tabular}


Table 2: Differences in likelihood to report scenarios on behalf of a friend or a stranger

\begin{tabular}{|c|c|c|c|c|c|c|}
\hline Scenario & M (SD) friend & $\begin{array}{l}\text { M (SD) } \\
\text { stranger }\end{array}$ & $d f$ & $t$ & $P$ & $\begin{array}{c}\text { Cohen's } \\
\text { d }\end{array}$ \\
\hline Xenophobia & $2.07(0.80)$ & $2.49(0.73)$ & 198 & 9.47 & $<.001$ & .55 \\
\hline Homophobia & $2.03(0.80)$ & $2.52(0.70)$ & 198 & 10.79 & $<.001$ & .65 \\
\hline Sexual Harassment & $1.76(0.85)$ & $2.03(0.88)$ & 199 & 7.13 & $<.001$ & .31 \\
\hline Islamophobia & $1.59(0.75)$ & $2.11(0.78)$ & 198 & 12.09 & $<.001$ & .68 \\
\hline $\begin{array}{l}\text { Non-consensual sex } \\
\text { tape }\end{array}$ & $1.49(0.70)$ & $2.09(0.83)$ & 199 & 11.03 & $<.001$ & .78 \\
\hline $\begin{array}{l}\text { Non-consensual } \\
\text { penetrative sex }\end{array}$ & $1.23(0.51)$ & $1.53(0.70)$ & 201 & 7.60 & .001 & .49 \\
\hline
\end{tabular}

Score 1 = yes, 2 = maybe, $3=$ no

Table 3: Themes and subthemes relating to student attitudes to harassment and assault

\begin{tabular}{ll}
\hline Theme & Subthemes \\
\hline Barriers to intervening & $\begin{array}{l}\text { Risks of intervening, Norms about } \\
\text { harassment. } \\
\text { Respecting the victim's decision, Reporting } \\
\text { backlash, Cultural norms about not reporting } \\
\text { abuse/seeking support, Personal experience } \\
\text { of not/reporting incidents, Perceived } \\
\text { seriousness of the event. }\end{array}$ \\
$\begin{array}{l}\text { Perception of perpetrators } \\
\text { Need for university community } \\
\text { education }\end{array}$ & \\
\hline
\end{tabular}

